\title{
Nonprobative photos rapidly lead people to believe claims about their own (and other people's) pasts
}

\author{
Brittany A. Cardwell ${ }^{1} \cdot$ Linda A. Henkel ${ }^{2}$. Maryanne Garry ${ }^{1}$. \\ Eryn J. Newman ${ }^{1}$ • Jeffrey L. Foster ${ }^{1}$
}

Published online: 23 March 2016

(C) Psychonomic Society, Inc. 2016

\begin{abstract}
Photos lead people to believe that both true and false events have happened to them, even when those photos provide no evidence that the events occurred. Research has shown that these nonprobative photos increase false beliefs when combined with misleading suggestions and repeated exposure to the photo or target event. We propose that photos exert similar effects without those factors, and test that proposition in five experiments. In Experiment 1, people saw the names of several animals and pretended to give food to or take food from each. Then people saw the animal names again, half with a photo of the animal and half alone, and decided whether they had an experience with each. The photos led people to believe they had experiences with the animals. Moreover, Experiments $2-5$ provided evidence that photos exerted these effects by making it easier to bring related thoughts and images to mind-a feeling that people mistook as evidence of genuine experience. In each experiment, photos led people to believe positive claims about the past (but not negative claims), consistent with evidence that feelings of ease selectively increase positive judgments. Experiment 4 also showed that photos (like other manipulations of ease) bias people's judgments broadly, producing false beliefs about other people's pasts. Finally, in Experiment 5, photos
\end{abstract}

Maryanne Garry

maryanne.garry@vuw.ac.nz

1 School of Psychology, Victoria University of Wellington, Box 600, Wellington, New Zealand

2 Psychology Department, Fairfield University, Fairfield, CT, USA exerted more powerful effects when they depicted unfamiliar animals, and thus could most help bring information to mind. These findings suggest that nonprobative photos can distort the past without other factors that encourage false beliefs, and that they operate by helping related thoughts and images come to mind.

Keywords Decision making $\cdot$ False memory $\cdot$ Memory · Judgment $\cdot$ Cognitive fluency

Photos can distort beliefs about the past. When photos are doctored to depict people involved in an event that never really happened, people can claim to remember the false event (Strange, Gerrie, \& Garry, 2005; Wade, Garry, Read, $\&$ Lindsay, 2002). Perhaps more surprising is that photos can yield these effects even when they do not provide "proof" the event occurred-that is, when the photos are related to the event, but provide no evidence that the event actually happened. In one study, for example, people were more likely to remember a suggested, but false, childhood prank (putting a slimy toy in their teacher's desk) if they saw a photo that related to but did not depict the prank (a photo of classmates from that grade; Lindsay, Hagen, Read, Wade, \& Garry, 2004).

One way these nonprobative photos should promote false beliefs is by making it easier for people to bring to mind related thoughts and images (e.g., about their long ago friends, teacher, and classroom), which people mistake as evidence they are remembering a real experience. Such a process fits with the source-monitoring framework, which proposes that when people think about personal experiences, they use the characteristics of the thoughts and images that come to mind to determine whether they are 
remembering an actual experience or one they merely imagined. Indeed, people conclude that they are remembering a genuine experience when the thoughts and images they retrieve are similar to those derived from perceptual experience - that is, when they are reasonably detailed given the age of the event, contain few records of effortful cognitive operations typical of imagining events, and come to mind relatively easily (Johnson, Hashtroudi, \& Lindsay, 1993; Lindsay, 2008, 2014).

It is clear that viewing photos can increase sourcemonitoring errors (see Henkel \& Carbuto, 2008). But much less clear is the extent to which photos promote those errors by themselves - that is, in isolation from other factors often paired with photos that also cultivate false beliefs. One such factor is the suggestion that the event really occurred. Claiming that a description of the target event, such as the slime prank, was provided by a trusted family member would make people especially likely to accept the thoughts and images that came to mind as evidence that the event had happened (Gilbert, 1991; Nickerson, 1998). Another factor is repeated exposure to the photo or event. In most of these studies, people saw the photo repeatedly, over the course of a week or more, and often were encouraged to elaborate on details of the event (Blandon-Gitlin \& Gerkens, 2010; Brown \& Marsh, 2008; Lindsay et al., 2004). Repetition and elaboration increase the ease and detail with which thoughts and images later come to mind (Jacoby \& Dallas, 1981; Suengas \& Johnson, 1988; Thomas, Bulevich, \& Loftus, 2003), and the passage of time causes the true source of those thoughts and images to fade. As a result, people are more likely to make a source-monitoring error, confusing imagination with reality (see Chrobak \& Zaragoza, 2008; Loftus, Miller, \& Burns, 1978).

Although these factors would bolster the influence of photos, there are reasons to believe that they are not necessary. That is, photos should distort people's beliefs about the past in the absence of suggestion, repetition, or the passage of time. Indeed, the source-monitoring framework predicts that nonprobative photos will encourage false beliefs if those photos can help people produce thoughts and images with phenomenal characteristics that feel like the result of genuine experience (Johnson et al., 1993; Lindsay, 2008, 2014). And, by providing semantic context, one phenomenal characteristic that photos should increase is the ease with which thoughts and images about an event come to mind-a change in processing that people often interpret as evidence of familiarity or truth (Collins \& Loftus, 1975; Whittlesea, 1993; for a review, see Alter \& Oppenheimer, 2009).

Indeed, there is evidence that when semantic context activates related information in memory, it leads people to believe personal experiences happened, even without the aid of repetition, suggestion, or much time passing by. In one study, people saw several lists of words, and after each list, decided whether a target word was on the list. When those target words (boat) appeared in highly related sentence fragments (e.g., The stormy seas tossed the...), people more often claimed that the words had been on the list than when the target words appeared in loosely related sentence fragments (e.g., He saved up his money and bought a...; Whittlesea, 1993). Put another way, the semantic context in which words appeared caused sourcemonitoring errors: Even though the sentence fragments did not reveal whether target words had actually been shown, they made it feel surprisingly easy to bring those words to mind - a feeling that people misattributed to having just seen the words (Westerman, 2008; Whittlesea \& Williams, 2001a, 2001b). These findings suggest that photos should distort beliefs about the past in the absence of repetition or suggestion, merely by increasing the ease with which related thoughts and images come to mind.

Recent work has supported that hypothesis. In one study, people read news headlines that described true events (John Paul sainthood process begins) and false events (Blair under fire for botched Baghdad rescue attempt: Won't step down) and then decided, within a few seconds, whether they remembered each event. People claimed to remember both true and false news events more often when the headlines appeared with related but nonprobative photos, such as a headshot of Tony Blair at a podium, compared to no photo (Strange, Garry, Bernstein, \& Lindsay, 2011). Just like the highly related sentence fragments, the photos may have made it easier to bring related thoughts and images to mind, which people interpreted as evidence that they remembered the events.

But whether photos operate in that way is ambiguous, in part because the study above did not test that mechanism, but also because it used misleading suggestions. Indeed, people were given no reason to suspect the events were false. This matters because people, by default, represent claims as true and are biased to selectively interpret related information (such as information provided in photos) in a way that confirms their hypotheses (Gilbert, 1991; Nickerson, 1998). Moreover, the headline-photo pairs were made up of familiar elements that were combined in a novel way (e.g., well-known political figures, such as Tony Blair, paired with a plausible news story). And when novel stimuli are made up of familiar elements, people are more likely to conclude that they have experienced those stimuli before (Devitt, Monk-Fromont, Schacter, \& Addis, 2015; Jones \& Jacoby, 2001). Together, these factors that increase the perceived truth 
and familiarity of events would have encouraged a less stringent style of source monitoring, lowering people's bar for accepting the ease of bringing information to mind as evidence the events had happened (Lindsay, 2008; Song \& Schwarz, 2008).

Other work has shown that nonprobative photos can yield similar effects without these suggestions. When people evaluate general knowledge claims (e.g., Macadamia nuts are in the same evolutionary family as peaches) that they know are a mix of true and false, they more often endorse claims that appear with related, but nonprobative, photos (e.g., a photo of macadamia nuts; Newman, Garry, Bernstein, Kantner, \& Lindsay, 2012). But these findings cannot tell us whether photos similarly distort people's judgments about their personal pasts. Perhaps more important is that these effects can be explained in ways that have nothing to do with the ease with which photos bring thoughts and images to mind. One possibility is that people scanned the photos in search of details that seemed like "evidence" for the claims at hand (Nickerson, 1998); another possibility is that people just felt more confident in claims when photos provided "extra" related information (Gill, Swann, \& Silvera, 1998).

Therefore, in five experiments we first tested the extent to which nonprobative photos rapidly distort people's beliefs about their pasts in the absence of suggestion, and then explored evidence for a mechanism through which photos exert their effects. Specifically, in Experiment 1 we asked people to imagine giving food to or taking food from unfamiliar animals. Then, during a later test, people saw the animal names again, except this time half of the animal names appeared with a photo of the animal and half appeared alone. When people saw each animal name, they decided whether a claim about their experience with it was true or false. Experiment 1 answered our primary research question by showing that nonprobative photos can encourage false beliefs about the past in the absence of repetition, suggestion, or the passage of time. In the remaining experiments, we examined the idea that photos operate by making it feel easier to bring related information to mind. First, in Experiments 2 and 3 we drew on research showing that easily bringing information to mind selectively increases positive judgments, and manipulated the valence of the claims that people evaluated. Second, on the basis of evidence that people use feelings of ease to make judgments broadly (not just about their own pasts), in Experiment 4 we tested whether these effects extended to when people evaluated claims about other people's pasts. Finally, in Experiment 5 we manipulated the familiarity of animal names to investigate whether photos exert their strongest effects when they can most help people bring information to mind.

\section{Experiment 1}

\section{Method}

\section{Subjects}

On the basis of our pilot work, we calculated that a sample size of 100 would balance precision and resource constraints. Ultimately, we recruited $89^{1}$ Victoria University of Wellington undergraduates (mean age $=18.82$ years, $S D=$ 1.24), who participated in exchange for course credit.

\section{Procedure}

We manipulated (within subjects) whether test items appeared with photos or alone. All instructions appeared on a computer, and each subject completed two phases - a study phase and a test phase.

Study phase During the study phase, we told subjects they would see the names of various zoo animals and that their task was to give food to some of the animals and take food from others. We created a list of 40 unfamiliar animals by searching the internet for unusual animals. We used unfamiliar animals for two reasons. First, the effects of nonprobative photos tend to be more powerful for judgments about unfamiliar stimuli (Newman et al., 2012). Second, we wanted to make it difficult for people to encode the events well because the test phase happened soon after the study phase, and there is evidence that well-encoded experiences are less susceptible to the influence of nondiagnostic feelings than are poorly - encoded experiences (Monin, 2003; Zaragoza \& Lane, 1998). The final set of animal names was a mix of mammals, reptiles, fish, and birds. To confirm that these animals were indeed unfamiliar and difficult to picture, we gathered data on how easily people could imagine the animals. We showed 83 Mechanical Turk subjects each animal name, one at a time, and asked them "How easily can you form a mental image of this animal?" The subjects answered using a scale from 1 (Very difficult) to 7 (Very easy), and their mean rating was $1.56(S D=1.34$, me$\operatorname{dian}=1)$.

\footnotetext{
${ }^{1}$ We recruited as many subjects as we could, given constraints on funds, the length of the semester, and our allocation from the departmental subject pool. In Experiments 2 and 3, we aimed to increase precision by collecting 200 observations per between-subjects cell. In Experiments 4 and 5, we used a different design that we suspected (on the basis of its similarity to the designs of our related work) would require fewer subjects per between-subjects cell. Experiments 2-5 were conducted using Amazon's Mechanical Turk. Mechanical Turk and the survey platform we used (Qualtrics) interact in such a way that it is possible to collect data from more subjects than requested, because some subjects go directly to the experiment on Qualtrics but never formally accept the job with Amazon - apparently because they forget to do so.
} 
When people started the study phase, animal names appeared one at a time on the computer screen along with an instruction that subjects should either give food to or take food from the animal (such as, "Give food to the Shoebill" and "Take food from the Hammerkop"). The animal names appeared randomly, counterbalanced to be paired equally often with the "give food" and "take food" instructions. When an instruction to give food appeared on the screen, subjects were to pick up a bean from the "feed bag" (a brown paper bag to the right of the computer screen) and move their hand forward to put the bean in the "food bowl" (a small white dish, also to the right of the computer screen); when instructions to take food appeared on the screen, subjects were to pick up a bean from the "food bowl" and move their hand backward to put the bean in the "feed bag." Other than the instructions, nothing appeared on the computer screen as subjects performed the actions. When subjects completed an action, they pressed the spacebar to reveal the next instruction. Finally, instructions reminded subjects to pay attention, because later they would answer more questions about the animals, though we did not specify the nature of those questions.

Test phase After the study phase, subjects completed a 30-s filler task in which they counted the number of dots in an image. Then the second phase, the memory test, began. Subjects learned that each animal name would appear on the screen, one at a time, like they had seen before - but this time, their job was to decide whether the claim "I gave food to this animal" was true or false. The subjects were also told that some of the animal names would appear with a photo of that animal and others would appear alone. Subjects practiced associating "true" responses with the "a" key (which was labeled with a " $T$ " sticker) and false responses with the "l" key (labeled with an "F" sticker), for four animal names not used in the main experiment. Then the test proper began. Animal names appeared one at a time in a random order in large black font against a white background. Half of the animal names appeared with a color photograph of the animal, and half appeared alone (see Fig. 1). The central object in the photo was the animal, but other contextual details (background scenes) were also visible. None of the photos depicted the animals eating. Animal names appeared equally often with and without photos.

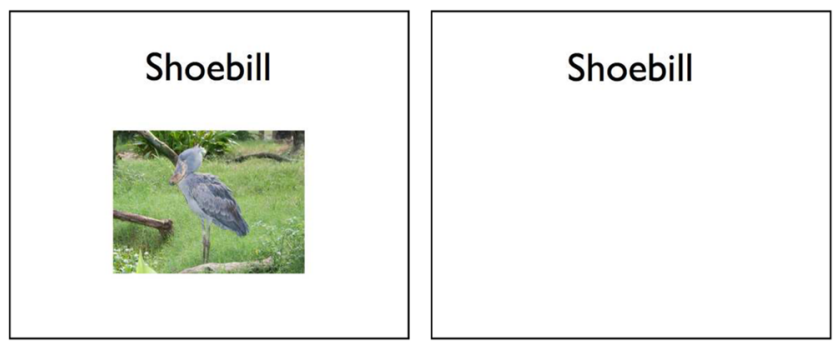

Fig. 1 Example of an animal name with and without a photo.
We pretested the extent to which these photos would make it feel easier for people to bring related thoughts and images to mind by showing a separate group of 34 Mechanical Turk subjects the animal names one at a time; half of the animal names appeared with a photo of the animal, and half appeared alone. When each animal name appeared on the screen, subjects rated how easy it felt to bring to mind information related to the animal, on a scale from 1 (Extremely difficult) to 6 (Extremely easy). Subjects rated it easier to bring related thoughts and images to mind when animal names appeared with photos $(M=3.01, S D=1.37)$ than when they appeared alone $(M=1.54, S D=0.57)$; that is, photos produced a raw effect size of $1.47,95 \%$ CI $[1.05,1.88], t(33)=7.16, p<.01$.

\section{Results and discussion}

We first addressed the question of the memory test: Was it difficult enough that people could not reliably decide which experiences they did or did not have? Accordingly, we calculated people's ability to discriminate between the animals they had given food to and taken food from, with higher scores representing better discrimination $(d$ '; Stanislaw \& Todorov, 1999). These discrimination scores measured people's ability to determine which events did versus did not happen and were derived from the hit rates (the proportions of times that people responded "true" to claims that were indeed true) and false alarm rates (the proportions of times people responded "true" to claims that were false). Discrimination is calculated by converting the hit and false alarm rates into $z$ scores, then subtracting those converted false alarms from the converted hits. The resulting value represents, in standard deviations, the amount of overlap between the signal and noise distributions, with higher values representing less overlap.

These discrimination scores were low, with a mean of 0.11 , $95 \%$ CI [0.01, 0.20], suggesting that people had trouble differentiating between experiences they did and did not have. The right two columns of Table 1 show discrimination scores (the other columns show the original hits and false alarms) when animals appeared with versus without photos. Calculating the difference between these two scores shows that photos trivially influenced discrimination, producing a raw effect size of $-0.03,95 \%$ CI $[-0.22,0.16]$. In null hypothesis terms, there was no effect of photos on discrimination, $t(88)=-0.32, p=.75$.

But our primary question was the extent to which nonprobative photos would lead people to say that claims about their experiences were true. To answer this question, we calculated people's bias to respond "true" ( $c$; Stanislaw $\&$ Todorov, 1999). Bias measures the criterion that people set for responding "true" and is derived from hit rates and false alarm rates. Bias is calculated by adding the $z$-converted hit and false alarm rates, dividing by 2 , then multiplying by -1 . The resulting value represents the number of 
Table 1 Means and standard deviations (in parentheses) for hits, false alarms, and $d^{\prime}$ measures in Experiments 1-3

\begin{tabular}{|c|c|c|c|c|c|c|c|}
\hline \multirow[b]{2}{*}{ Exp. } & \multirow[b]{2}{*}{ Claim } & \multicolumn{2}{|l|}{ Hits } & \multicolumn{2}{|c|}{ False Alarms } & \multicolumn{2}{|c|}{ Sensitivity $\left(d^{\prime}\right)$} \\
\hline & & Photo & No Photo & Photo & No Photo & Photo & No Photo \\
\hline 1 & "Gave food" & $.57(.16)$ & $.51(.17)$ & $.54(.18)$ & $.47(.17)$ & $0.09(0.57)$ & $0.12(0.69)$ \\
\hline \multirow[t]{2}{*}{2} & "Gave food" & $.57(.21)$ & $.52(.22)$ & $.52(.22)$ & $.49(.20)$ & $0.17(0.83)$ & $0.12(0.96)$ \\
\hline & "Took food" & $.52(.21)$ & $.52(.21)$ & $.47(.21)$ & $.46(.21)$ & $0.17(0.95)$ & $0.21(0.98)$ \\
\hline \multirow[t]{2}{*}{3} & "Healthy" & $.58(.21)$ & $.53(.23)$ & $.50(.22)$ & $.44(.23)$ & $0.26(0.90)$ & $0.32(0.99)$ \\
\hline & "Unhealthy" & $.53(.22)$ & $.52(.21)$ & $.48(.23)$ & $.50(.22)$ & $0.16(0.94)$ & $0.07(0.96)$ \\
\hline
\end{tabular}

Bias (c) values appear in the figures for Experiments 1-3.

standard deviations between people's criterion and the halfway point between the signal and noise distributions (i.e., what would be a neutral criterion). Negative values of bias represent a liberal criterion (a tendency to respond "true"), and positive values represent a conservative criterion (a tendency to respond "false"). We performed these bias calculations separately for animal names that appeared with photos and those that appeared alone. Then we calculated the raw effect of photos by subtracting people's bias scores in the no photo trials from those in the photo trials. We display the results in Fig. 2, which shows that photos led people to respond true more often to the claim that they gave food to animals, a raw effect size of $-0.18,95 \%$ CI [$0.28,-0.07]$. In null hypothesis terms, there was an effect of photos, $t(88)=-3.26, p<.01$.

These findings show that nonprobative photos distort people's beliefs about their pasts even in the absence of misleading suggestions, repetition, or the passage of much time. In Experiments 2-5, we examined the mechanisms driving this effect. Specifically, we investigated the idea that photos promote these source-monitoring errors by making related thoughts and images come to mind more easily, which people mistake for evidence of genuine experience (Johnson et al., 1993; Whittlesea, 1993).
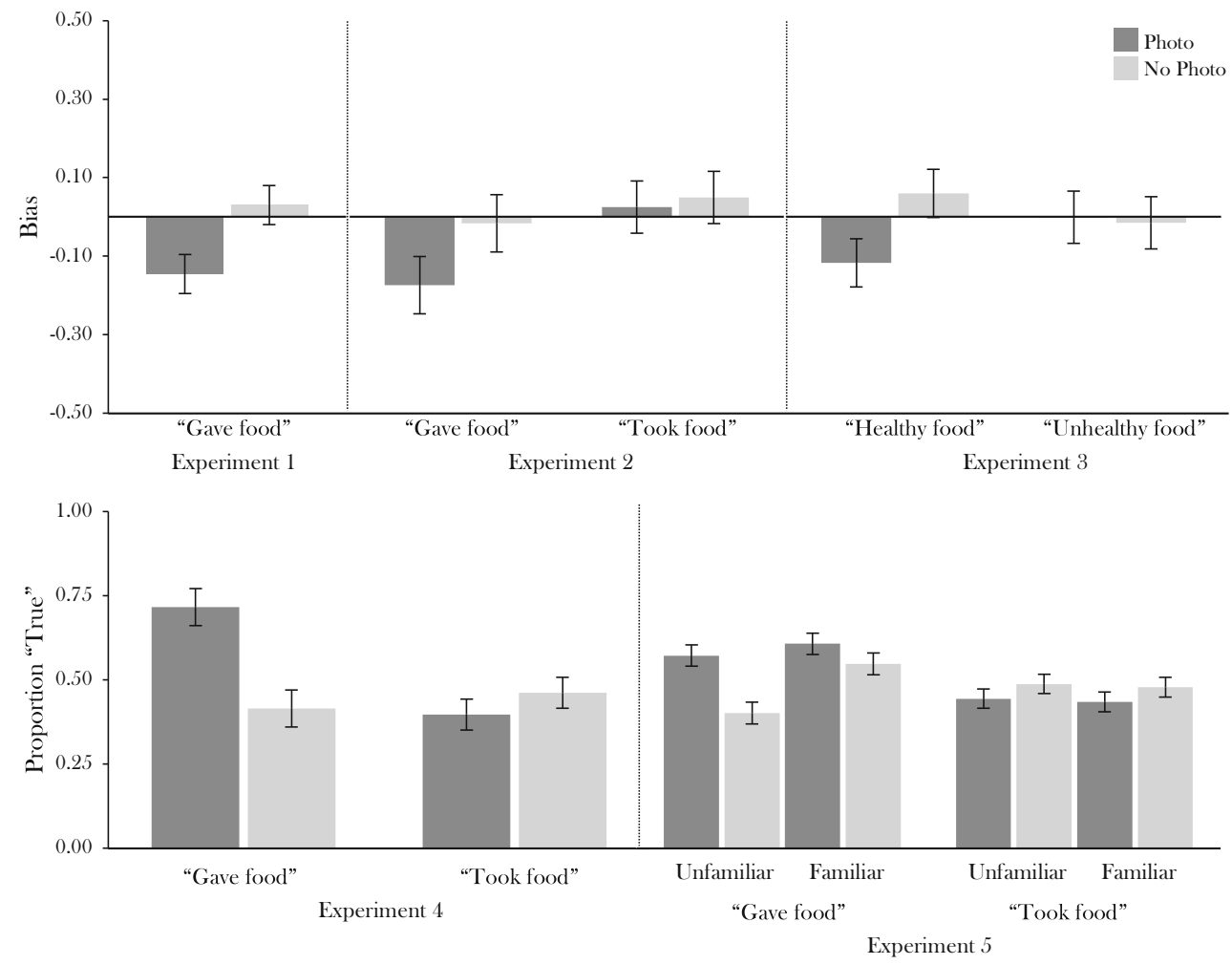

Fig. 2 Top panel: Bias scores for responses to positive and negative claims when animal names appeared with photos or alone (Exps. 1-3). Bottom panel: Proportions of "true" responses to positive and negative claims when unfamiliar (Exps. 4 and 5) and familiar (Exp. 5) animals

appeared with or without photos. Error bars show $95 \%$ within-subject confidence intervals for the photo/no photo effects (see Masson \& Loftus, 2003). 
If photos work through such a mechanism, then there are reasons to believe that photos would selectively lead people to think they had positive experiences (such as having given food to animals), but not negative experiences (such as if people had decided whether they had taken food away from animals). Indeed, when information comes to mind easily, people tend to see it not just as more familiar or true, but as generally more positive-more attractive, pleasant, and liked (for reviews, see Reber, Schwarz, \& Winkielman, 2004; Schwarz, 2004; Winkielman, Schwarz, Fazendeiro, \& Reber, 2003). Cognitive ease even automatically activates the facial muscles associated with positive affect, suggesting that ease puts a positive spin on people's judgments because it is inherently pleasing (Winkielman \& Cacioppo, 2001; Winkielman, Halberstadt, Fazendeiro, \& Catty, 2006). In fact, people tend not to use feelings of ease as evidence for negative attributes of targets, perhaps due to the mismatch between the positive feelings and the negative focus of the judgment (Reber, Winkielman, \& Schwarz, 1998; Seamon, McKenna, \& Binder, 1998).

This literature suggests that if photos operate by helping people more easily bring related information to mind, they should lead people to believe positive claims about their experiences, but not negative claims. To examine that hypothesis, during the test phase of Experiment 2, we asked people to judge a claim about either a positive experience ("I gave food to this animal") or a more negative experience ("I took food from this animal"). We predicted that photos would lead people to claim that they "gave food" to animals, but not that they "took food."

\section{Experiment 2}

\section{Method}

Subjects We recruited 416 subjects using Amazon's Mechanical Turk (mean age $=32.46$ years, $S D=11.34$ ).

Procedure We used a 2 (Photo: photo, no photo) $\times 2$ (Claim: gave food, took food) mixed design, with Photo as the within-subject factor and Claim as the betweensubjects factor.

The procedure departed from that of Experiment 1 in four ways. First, subjects completed the experiment online through Qualtrics survey software (Qualtrics, Provo, UT). Second, during the study phase, when subjects gave food to and took food from each animal, they responded by selecting one of two options, which said "give food" or "take food," counterbalanced (between subjects) to appear first or second. Third, during the test phase, some subjects judged the claim "I gave food to this animal," and others judged the claim "I took food from this animal." Giving food to an animal is a positive experience that involves providing nutrition, whereas taking nutrition away would be a more negative experience. Subjects responded to the claims by selecting one of two options that said "true" or "false" and appeared below each animal name, counterbalanced (between subjects) to appear on the right- or left-hand side of the screen.

Finally, after the test phase, subjects read an article that had a secret word in it, and on the following page of the survey, they were asked to produce that secret word; successful subjects passed this attention check (Oppenheimer, Meyvis, \& Davidenko, 2009). Then subjects indicated whether they had maximized their web browser, used their "back" or "refresh" button, completed the experiment in a single session, engaged in other tasks, spoken to others, worked in an environment free of noise and distraction and without help, written any of the animal names down during the study phase, or used a search engine to look them up. We encouraged truthful responses by promising the subjects we would compensate them in full regardless of their answers.

\section{Results and discussion}

When we included subjects who failed our attention measure, ${ }^{2}$ it did not change the overall pattern of results in this (or subsequent) experiments; therefore, we retained them in the dataset. As in Experiment 1, the subjects' discrimination scores were low, whether they responded to the "gave food" claim $(0.14,95 \%$ CI $[0.04,0.25])$ or to the "took food" claim $(0.19,95 \%$ CI $[0.08,0.31])$. Photos trivially affected discrimination; for the "gave food" claim, the photos produced a raw effect of $0.04,95 \% \mathrm{CI}[-0.09,0.19]$, and for the "took food" claim, they produced a raw effect of $-0.04,95 \%$ CI $[-0.17$, 0.09]. In null hypothesis terms, there was no Photo $\times$ Claim interaction, $F(1,414)=0.76, p=.38$, nor were there main effects of Photo, $F(1,414)=0.00, p=.96$, or Claim, $F(1,414)=0.38, p=.54$.

\footnotetext{
${ }^{2}$ In Experiment 2, $38 \%$ of the subjects failed the attention check. Experiments 3, 4, and 5 had similar failure rates $(38 \%, 45 \%$, and $40 \%$, respectively). These rates are above or at the high end of those reported in research investigating Mechanical Turk as a subject pool (10 \%-39 \%; Downs, Holbrook, Sheng, \& Cranor, 2010; Goodman, Cryder, \& Cheema, 2013; Kapelner \& Chandler, 2010). We suspect that our high failure rates are an artifact of the attention check we used. The article that subjects read was six paragraphs long and came at the end of the experiment, when subjects would be most fatigued and tempted to skim or skip material (see Downs et al., 2010). Moreover, the effort involved in the reading task was different from that of judging the truth of claims. An attention check more similar to the main experimental task might have produced lower failure rates and provided more reliable information for determining whether subjects had attended to that task. Finally, there is evidence that the quality of data is not improved by excluding on the basis of just one attention check, suggesting that the data of subjects who passed our attention check were not necessarily better than the data of those who failed (Berinsky, Margolis, \& Sances, 2014).
} 
We now turn to our primary question: To what extent did nonprobative photos affect people's beliefs in positive and negative claims about their pasts? Figure 2 shows the answer to this question: Photos led people to respond "true" more often to the positive claim, but not to the negative claim. For the "gave food" claim, photos produced a raw effect size of $0.16,95 \%$ CI $[-0.26,-0.05]$, but for the "took food" claim, they produced an effect size of $-0.02,95 \%$ CI $[-0.12,0.07]$. In null hypothesis terms, there was a trend toward a Photo $x$ Claim interaction, $F(1,414)=3.55, p<.06$.

We replicated these patterns with three additional groups of Mechanical Turk subjects. To arrive at a more precise estimate of the size of the photo bias, we subjected the data from these three additional experiments and the data from Experiment 1 to random effects model mini meta-analyses (Cumming, 2012). We report the results in Table 2, which shows the estimated raw effect sizes (ES) and $95 \%$ confidence intervals (CIs) for the effects of photos on positive and negative claims. As the table shows, photos produced larger estimated effect sizes for the positive than for the negative claim - findings that are consistent with those reported here.

Photos selectively led people to respond "true" to claims about positive experiences. This pattern supports a mechanism in which photos made related thoughts and images come more easily to mind and, in doing so, produced positive feelings that matched the positive actions suggested in the "gave food" claim (Reber et al., 1998; Seamon et al., 1998). But a confound clouds that interpretation. Perhaps it was not the positive outcome of the action that mattered (providing nutrition), but the positive connotations of the action itself (giving). Indeed, we know that positive feelings, such as liking, are linked with the desire to approach a stimulus (Cacioppo, Gardner, \& Berntson, 1999; Elliot, 2006; Lang, Bradley, \& Cuthbert, 1990). We also know that the physiological responses associated with the desire to approach come about when people's bodies are merely positioned in a way similar to how one might approach a stimulus (such as when people lean forward; Price, Dieckman, \& Harmon-Jones, 2012). Considered together, these findings raise the possibility that thinking about actions associated with approaching a stimulus (such as moving toward an animal to give it food) might have produced positive feelings that matched the feelings the photos produced.

To address this issue, in Experiment 3 people judged one of two claims that both used the word "gave," but that referred to either a positive or a negative outcome of the action. Specifically, during the study phase we instructed people to give "healthy food" and to give "unhealthy food" to animals. Then, during the test phase, some people judged the claim "I gave healthy food to this animal" and others judged the claim "I gave unhealthy food to this animal." We predicted that if the positive outcome of the action is what matters, and not merely the action of giving, photos should lead people to respond "true" more often only to the "healthy food" claim.

\section{Experiment 3}

\section{Method}

Subjects We recruited 458 subjects from Mechanical Turk (mean age $=33.15, S D=11.54)$.

Procedure We used a 2 (Photo: photo, no photo) $\times 2$ (Claim: healthy food, unhealthy food) mixed design, with Photo as the within-subject factor and Claim as the between-subjects factor.

The procedure followed that of Experiment 2, except that subjects were told that their task was to give "healthy food" or "unhealthy food" to the animals. We also explained what we meant by healthy and unhealthy food. Specifically, we told subjects "You have an assortment of food that the animals can eat. Some of it is healthy (the people-equivalent of vegetables), and some of it is unhealthy (the people-equivalent of donuts or french fries)." This change meant that during the study phase, subjects clicked one of two options ("healthy food" or "unhealthy food"), and that during the test phase some subjects judged the claim "I gave healthy food to this

Table 2 Summary of the results from each meta-analysis for Experiments 1 and 2

\begin{tabular}{|c|c|c|c|c|c|c|}
\hline \multirow[b]{2}{*}{ Claim } & \multirow[b]{2}{*}{ ES } & \multicolumn{2}{|c|}{$95 \% \mathrm{CI}$} & \multirow[b]{2}{*}{$z$} & \multirow[b]{2}{*}{$p$} & \multirow{2}{*}{$\begin{array}{l}\text { Experiments Included in Calculating ES, } \\
\text { With Sample Size in Parentheses }\end{array}$} \\
\hline & & LL & UL & & & \\
\hline Positive (“Gave food”) & -0.11 & -0.15 & -0.06 & -4.62 & $<.01$ & $\begin{array}{l}1^{\mathrm{a}}(89), 2^{\mathrm{a}}(205), 2 \mathrm{R} 1^{\mathrm{b}}(256), 2 \mathrm{R} 2^{\mathrm{b}} \\
\quad(184), 2 \mathrm{R} 3^{\mathrm{b}}(183)\end{array}$ \\
\hline Negative (“Took food”) & 0.01 & -0.05 & 0.06 & 0.25 & .81 & $\begin{array}{l}2^{\mathrm{a}}(211), 2 \mathrm{R} 1^{\mathrm{b}}(261), 2 \mathrm{R} 2^{\mathrm{b}}(181), \\
\quad 2 \mathrm{R} 3^{\mathrm{b}}(183)\end{array}$ \\
\hline
\end{tabular}

Meta-analyses split by claims across Experiments 1 and 2. ES = effect size, the difference between the photo and no photo bias means. Negative effect size $=$ bias to respond "true"; Positive effect size $=$ bias to respond "false." LL and UL $=$ lower and upper limits of the $95 \%$ confidence interval $(\mathrm{CI})$ of the ES. $\mathrm{R}=$ replication of an experiment $(\mathrm{R} 1$ = first replication, $\mathrm{R} 2$ = second replication, etc. $)$. Experiment $2 \mathrm{R} 1-\mathrm{R} 3$ used the same method as Experiment 2. ${ }^{\mathrm{a}}$ Experiments and replications reported in the main text. ${ }^{\mathrm{b}}$ Replications not otherwise reported in the main text. 
animal," and others judged the claim "I gave unhealthy food to this animal."

\section{Results and discussion}

As in Experiments 1 and 2, people's discrimination scores were relatively low for both the "healthy food" claim $(0.29$, $95 \%$ CI $[0.18,0.40])$ and the "unhealthy food" claim $(0.12$, $95 \%$ CI $[0.01,0.23]$ ) - but note that discrimination was higher for the positive than for the negative claim (in null hypothesis terms, a main effect of claim, $F(1,456)=4.92$, $p=.03$ ). Photos also trivially affected discrimination, though they did so more for the "unhealthy food" claim than for the "healthy food" claim; for the "healthy food" claim, photos produced a raw effect of $-0.05,95 \% \mathrm{CI}[-$ $0.17,0.07]$, and for the "unhealthy food" claim, photos produced a raw effect of $0.09,95 \%$ CI $[-0.02,0.21]$. In null hypothesis terms, there was no Photo $\times$ Claim interaction, though there was a tendency for photos to produce better discrimination for the negative claim, $F(1,456)=$ 2.91, $p=.09$.

But, more to the point, we found that photos encouraged people to think that only the claims describing the positive outcomes of an action (giving healthy food) were true - a finding that suggests that the patterns from Experiment 2 were not tied to the actions associated with the word "gave," but to the outcome of those actions. That is, for the "healthy food" claim, photos biased people to respond "true," producing a raw effect size of $-0.18,95 \%$ CI $[-0.26,-0.09]$, but for the "unhealthy food" claim they did not, producing a raw effect size of 0.01 , $95 \% \mathrm{CI}[-0.08,0.11]$. In null hypothesis terms, there was a Photo $\times$ Claim interaction, $F(1,456)=8.69, p<.01$.

Still, another possibility is that the claims we called "positive" simply described relatively more plausible events; if so, an alternative interpretation is that the photos selectively led people to believe plausible events (see Blandon-Gitlin \& Gerkens, 2010). One way to investigate that hypothesis would be to compare people's overall tendencies to respond "true" across claims, assuming that the belief that an event really happened captures its plausibility (Scoboria, Mazzoni, Kirsch, \& Relyea, 2004). We applied this logic to the results of Experiment 2. As Fig. 2 shows, the results fit with the idea that giving food to animals was more plausible than taking food. Indeed, we calculated the difference between people's biases to respond "true" to the two claims and found that, on the whole, people responded "true" to the "gave food" claim more than to the "took food" claim (a raw effect of $-.13,95 \%$ CI $[-.21,-.05], t(414)=-3.22, p<.01)$. But that pattern did not emerge in the results of Experiment 3. Instead, the figure shows a pattern suggesting that the two events were similarly plausible. People responded "true" to a similar extent, whether they were judging the "healthy food" or the "unhealthy food" claim (a raw effect of $-.02,95 \%$ CI $[-.12, .08]$, $t(456)=-0.42, p=.68)$. Therefore, a plausibility explanation is not a sufficient account of the valence effects.

Nonetheless, we further examined this plausibility explanation by asking a separate group of subjects $(n=246)$ to decide how easily they could form a mental image of the events described by the claims. We showed subjects ten animal names without photos. For each animal, subjects rated how easily they could form a mental image of (between subjects) "giving food to the animal," "taking food from the animal," "giving healthy food to the animal," or "giving unhealthy food to the animal." Subjects made these ratings on a scale from 1 (Very difficult) to 7 (Very easy). If anything, subjects rated it more difficult to imagine the positive than the negative claims. The subjects' ratings for "giving food" $(M=$ $2.28, S D=1.22,95 \% \mathrm{CI}[1.97,2.59])$ and "giving healthy food" $(M=2.24, S D=1.45,95 \%$ CI $[1.88,2.60])$ were numerically lower than their ratings for "taking food" ( $M=$ $2.65, S D=1.30,95 \% \mathrm{CI}[2.31,2.99])$ and "giving unhealthy food" ( $M=2.40, S D=1.24,95 \%$ CI $[2.08,2.72])$. In null hypothesis terms, there was no effect of Claim, $F(3,242)=$ $1.21, p=.31$.

Considered as a whole, these data provide evidence against the idea that photos merely increased belief in plausible experiences. Instead, the patterns from Experiments 2 and 3 fit better with the idea that nonprobative photos selectively lead people to believe claims about their positive experiences - a finding in line with a mechanism in which photos help people bring related thoughts and images to mind.

Such a mechanism relies less on mistakes about the source of the details that photos help people generate about the event, and more on mistakes about the ease with which those details come to mind. Therefore, one prediction is that photos would produce similar effects if people were to guess about what experiences other people had in the past - that is, if people were in a situation in which they had no reason to interpret the details that came to mind as evidence that they themselves were remembering events. Indeed, people draw on cognitive ease broadly, not only as evidence of personal experience, but also as evidence of truth, value, frequency, beauty, closeness, intelligence, loudness, and fame (and the list goes on; for reviews, see Alter \& Oppenheimer, 2009; Jacoby, Kelley, \& Dywan, 1989; Winkielman et al., 2003). Ease can be "about" so many different things because the way that people interpret it is constrained by what seems to be the most plausible cause, given the task at hand (Higgins, 1998; Schwarz, 2004). If a task encourages people to judge loudness, ease seems to relate to loudness; if a task encourages people to judge fame, ease seems to relate to fame; and if a task encourages people to judge the past (as in Exps. 1-3), ease seems to relate to the past (Jacoby et al., 1989).

What is more, research has shown that people draw on feelings of ease to make judgments about other people's pasts: "Ease" makes people more confident that childhood 
experiences have happened to them and to other people (Bernstein, Godfrey, \& Loftus, 2009; Bernstein, Whittlesea, \& Loftus, 2002). Therefore, if photos operate by making it easier to bring related thoughts and images to mind, people should draw on those feelings as evidence even when their task is to evaluate other people's pasts, instead of their own. We examined that hypothesis in Experiment 4 by asking people to guess whether other people had experiences with the animals at the zoo. Specifically, people decided whether it was true that other people "gave food to" or "took food from" animals. We predicted that photos would lead people to say other people had positive, but not negative, experiences in the past.

\section{Experiment 4}

\section{Method}

Subjects We recruited 282 subjects using Amazon's Mechanical Turk (mean age $=30.49$ years, $S D=11.27$ ).

Procedure We used a 2 (Photo: photo, no photo) $\times 2$ (Claim: gave food, took food) mixed design, with Photo as the withinsubject factor and Claim as the between-subjects factor. The procedure followed that of Experiment 2, except that we removed the study phase and changed the instructions accordingly. Rather than asking subjects to remember which animals they gave food to and took food from, we explained that we had instructed another group of Mechanical Turk workers to "give food to" or "take food from" each animal. Then we told half of the subjects that their task was to judge whether the claim "The workers gave food to this animal" was true or false, and told the other half that their task was to judge the claim "The workers took food from this animal." This setup meant that subjects could not draw on their own experience to decide whether the claims were true, and would instead have to guess.

\section{Results and discussion}

Because people did not have the experience with zoo animals themselves, but guessed about the experiences of others, it was not possible to calculate measures of discrimination and bias. Instead, we calculated for each subject the proportion of "true" responses, grouped those responses according to whether the animals had appeared with photos or alone, and then further grouped them according to whether subjects had judged the "gave food" or "took food" claim.

As Fig. 2 shows, when people guessed about the experiences others had, photos produced patterns similar to when people decided what they themselves had experienced (in Exps. 1-3). That is, photos led people to respond "true" more often to the positive claim but not to the negative claim. For the "gave food" claim, photos produced a raw effect size of $.30,95 \%$ CI $[.25, .36]$, but for the "took food" claim they produced a raw effect size of $-.07,95 \% \mathrm{CI}[-.13, .00]$. In null hypothesis terms, there was a Photo $\times$ Claim interaction, $F(1$, $280)=70.86, p<.01$. Note that these effect sizes are larger than those reported in Experiments 1-3. Our speculation for this difference is that in Experiments 1-3, people could at least attempt to draw on their memories to evaluate the claims; that is, people had a source of information other than the photos (however poor their memories were; Monin, 2003; Unkelbach, 2007). By contrast, in Experiment 4 people had only the photos as a source of information, allowing the photos to wield more power.

Coupled with the findings in Experiments 1-3, these findings suggest that photos make positive experiences seem more believable, regardless of whether those experiences refer to one's own past or to another person's past. These effects support the hypothesis that photos cause rapid source-monitoring errors by making it feel easier for people to bring related information to mind, but an alternative mechanism remains. We know that people can mistake positive feelings arising from viewing attractive stimuli as evidence of prior experience (Garcia-Marques, Mackie, Claypool, \& Garcia-Marques, 2013; Monin, 2003). Those effects raise the possibility that people were attracted to the colorful, interesting photos and mistook those feelings from attraction - rather than feelings of ease - as evidence for positive claims about the past. Such a mechanism would not require photos to help people bring related thoughts and images to mind, and would predict that photos depicting familiar animals that people could easily bring to mind (such as a zebra) would yield effects comparable to photos depicting unfamiliar animals that people struggled to bring to mind (e.g., a shoebill). By contrast, if photos work by helping people bring related information to mind, they should exert stronger effects when they can most help - namely, when the animals are unfamiliar. We investigated these competing mechanisms in Experiment 5 by showing people both familiar and unfamiliar animals.

\section{Experiment 5}

\section{Method}

Subjects We recruited 314 subjects using Amazon's Mechanical Turk (mean age $=31.44$ years, $S D=11.15$ ).

Procedure We used a 2 (Photo: photo, no photo) $\times 2$ (Claim: gave food, took food) $\times 2$ (Familiarity: familiar animals, unfamiliar animals) mixed design, with Photo and Familiarity as within-subject factors and Claim as the between-subjects factor. Using the method described in Experiment 1, we developed a new set of 40 familiar animal names. We also 
examined the extent to which photos made people feel they could bring to mind thoughts and images about these familiar animals. Accordingly, a separate group of 38 Mechanical Turk subjects saw the familiar animal names, one at a time; half of the animal names appeared with a photo of the animal, and half appeared alone. Subjects rated how easy it felt to bring to mind information related to the animals using a scale from 1 (Extremely difficult) to 6 (Extremely easy). In line with our idea that photos of familiar animals should provide little help with bringing related information to mind, subjects' ratings were similar whether the animal names appeared with photos $(M=5.24, S D=0.72)$ or alone $(M=5.08, S D=0.81)$; photos produced a raw effect size of $0.16,95 \% \mathrm{CI}[-0.02,0.34], t(37)$ $=1.85, p=.07$. Moreover, these data provide evidence consistent with the idea that it should be harder for people to bring to mind thoughts and images about unfamiliar animals than about familiar animals. The effect of photos for familiar animals reported here is smaller than that for the unfamiliar animals reported in Experiment 1, in which the photos produced a raw effect size of $1.47,95 \% \mathrm{CI}[1.05,1.88], t(33)=7.16, p<$ .01 . In null hypothesis terms, there was a Photo $\times$ Familiarity interaction, $F(1,70)=36.60, p<.01$.

Subjects saw 80 animal names, comprising a block of these 40 familiar animals plus a block of the 40 unfamiliar animals used in Experiments 1-4. We counterbalanced the order of the blocks between subjects. The procedure was otherwise identical to that of Experiment 4.

\section{Results and discussion}

Figure 2 shows three important findings. First, we found patterns consistent with those reported in Experiments 1-4: For unfamiliar animals, photos led people to respond "true" more often to the "gave food" claim, but not to the "took food" claim. Second, in line with our hypothesis, photos exerted stronger effects for unfamiliar animals - that is, when photos could most help people bring related information to mind (but as the figure shows, only for the positive claim). Third, a closer look at the patterns on the "gave food" side of the figure suggests that even in the absence of photos, people responded "true" more when it was easier to bring information to mind (when the animals were familiar). Table 3 also shows the raw effect sizes, confidence intervals, and (in null hypothesis terms) a Photo $\times$ Claim $\times$ Familiarity interaction, $F(1,312)$ $=6.61, p=.01$.

We replicated these patterns with another group of Mechanical Turk subjects. To arrive at a more precise estimate of the sizes of the photo effects for familiar and unfamiliar animals, we subjected the data from those experiments and from Experiment 4 to random effects model mini meta-analyses. We report those results, which are consistent with those reported here, in Table 4 (Cumming, 2012).

Experiment 5 shows that when photos could most help people bring related information to mind, they more powerfully affected people's beliefs in the positive claims. This finding converges with those of Experiments 2-4 to show that photos wield their effects by increasing the ease with which people can bring related information to mind.

\section{General discussion}

In five experiments, nonprobative photos led people to claim that personal experiences happened, even in the absence of other factors that are known to distort beliefs about the past. Across the experiments, we found evidence in line with the idea that photos caused these rapid source-monitoring errors by making it easier for people to bring related thoughts and images to mind. Photos led people to believe positive claims about the past, but not negative claims (Exps. 2-5); produced similar patterns when the claims were not about one's own past but about other people's pasts (Exps. 4-5); and exerted their strongest effects when they could most help people bring related thoughts and images to mind (Exp. 5). These results support the source-monitoring framework by showing that through merely increasing the ease with which information comes to mind, photos produce mental products that people

Table 3 Proportions of "true" responses to claims when familiar and unfamiliar animals appeared with or without photos

\begin{tabular}{|c|c|c|c|c|c|c|c|c|c|c|c|}
\hline \multirow{2}{*}{$\begin{array}{l}\text { “Gave Food” } \\
\text { Effect }\end{array}$} & \multirow[b]{2}{*}{ ES } & \multicolumn{2}{|c|}{$95 \%$ CI } & \multirow[b]{2}{*}{$t$} & \multirow[b]{2}{*}{$p$} & \multirow{2}{*}{$\begin{array}{l}\text { "Took Food" } \\
\text { Effect }\end{array}$} & \multirow[b]{2}{*}{ ES } & \multicolumn{2}{|c|}{$95 \% \mathrm{CI}$} & \multirow[b]{2}{*}{$t$} & \multirow[b]{2}{*}{$p$} \\
\hline & & LL & UL & & & & & LL & UL & & \\
\hline Photo & & & & & & Photo & & & & & \\
\hline Unfamiliar & .17 & .11 & .23 & 5.29 & $<.01$ & Unfamiliar & -.04 & -.11 & .02 & -1.31 & .19 \\
\hline Familiar & .06 & .02 & .10 & 3.29 & $<.01$ & Familiar & -.04 & -.08 & .00 & -2.14 & .03 \\
\hline Familiarity & & & & & & Familiarity & & & & & \\
\hline Photo & .04 & .00 & .08 & 1.64 & .10 & Photo & -.01 & -.05 & .03 & -0.53 & .59 \\
\hline No photo & .15 & .09 & .20 & 5.14 & $<.01$ & No photo & -.01 & -.06 & .04 & -0.47 & .64 \\
\hline
\end{tabular}

Raw effect sizes (ES), $95 \%$ confidence intervals (CIs), $t$ and $p$ values are shown for each comparison. 
Table 4 Summary of the results from each meta-analysis for Experiments 4 and 5

\begin{tabular}{|c|c|c|c|c|c|c|c|}
\hline \multirow[b]{2}{*}{ Claim } & \multirow[b]{2}{*}{ Manipulation } & \multirow[b]{2}{*}{ ES } & \multicolumn{2}{|c|}{$95 \% \mathrm{CI}$} & \multirow[b]{2}{*}{$z$} & \multirow[b]{2}{*}{$p$} & \multirow{2}{*}{$\begin{array}{l}\text { Experiments Included in } \\
\text { Calculating ES, With Sample } \\
\text { Size in Parentheses }\end{array}$} \\
\hline & & & LL & UL & & & \\
\hline \multirow[t]{2}{*}{ Positive ("Gave food") } & Photo effect (Unfamiliar names) & .26 & .18 & .34 & 6.53 & $<.01$ & $4^{\mathrm{a}}(141), 5^{\mathrm{a}}(160), 5 \mathrm{R} 1^{\mathrm{b}}(172)$ \\
\hline & Photo effect (Familiar names) & .04 & .02 & .07 & 3.29 & $<.01$ & $5^{\mathrm{a}}(160), 5 \mathrm{R} 1^{\mathrm{b}}(172)$ \\
\hline \multirow[t]{2}{*}{ Negative ("Took food”) } & Photo effect (Unfamiliar names) & -.05 & -.08 & -.01 & -2.63 & .01 & $4^{\mathrm{a}}(141), 5^{\mathrm{a}}(154), 5 \mathrm{R} 1^{\mathrm{b}}(163)$ \\
\hline & Photo effect (Familiar names) & -.03 & -.06 & .01 & -1.55 & .12 & $5^{\mathrm{a}}(154), 5 \mathrm{R} 1^{\mathrm{b}}(163)$ \\
\hline
\end{tabular}

Meta-analyses are split by the manipulations used in Experiments 4 and 5. ES $=$ effect size, the difference between the photo and no photo means. Positive effect size $=$ higher proportion of "true" responses when animal names appeared with photos rather than alone. LL and UL $=$ lower and upper limits of the $95 \%$ confidence interval $(\mathrm{CI})$ of the $\mathrm{ES} . \mathrm{R}=$ replication of an experiment $(\mathrm{R} 1=$ first replication). Experiment $5 \mathrm{R} 1 \mathrm{used}$ the same method as Experiment 5. ${ }^{a}$ Experiments and replications reported in the main text. ${ }^{\mathrm{b}}$ Replications not otherwise reported in the main text.

mistake for evidence of genuine experience (Johnson et al., 1993; Lindsay, 2008, 2014; Strange et al., 2011).

The findings also extend the source-monitoring framework by qualifying that proposition. Photos did not lead people to believe that just any experiences happened. Instead, photos selectively led people to believe claims about positive experiences - a pattern consistent with a mechanism in which photos increase feelings of ease in the present, which people misattribute to the past (Whittlesea, 1993). That is, because feelings of ease are inherently positive, photos that cause those feelings should lead people to see the past through a positive lens (Topolinski, Likowski, Weyers, \& Strack, 2009; Winkielman \& Cacioppo, 2001). In fact, the negative sides of the plots in Fig. 2 (particularly in Exps. 4 and 5) show that, if anything, photos made negative claims less believable. That pattern fits with recent work showing that pairing trivia claims with unrelated photos (e.g., a claim about macadamia nuts with a picture of a trash can) can also decrease belief (Newman et al., 2015). The unrelated photos probably worked by making it feel difficult to bring related information to mind, which people interpreted as evidence against the idea that the claims were true (Unkelbach, 2007). Likewise, even though our photos made it easy to bring related information to mind, that process would have produced positive feelings that people interpreted as evidence against the negative claims.

A critic might wonder how these valence effects can be reconciled with research showing that photos increase belief in personally experienced events that are arguably negative, such as getting in trouble for pulling a prank at school or nearly being hit by a car as a child (Blandon-Gitlin \& Gerkens, 2010; Lindsay et al., 2004). Those apparent discrepancies could arise exactly because prior work had paired photos with other factors that distorted beliefs. For example, when repetition and elaboration increase the ease and detail with which events later come to mind, they should overshadow any initial doubts in negative events that photos caused (see Thomas \& Loftus, 2002). There are also reasons to believe that misleading suggestions would trump the positive effects of photos. We know that people are biased to search for evidence consistent with their beliefs and to discount evidence that refutes them (Nickerson, 1998). When misleading suggestions increase belief in a negative event, then, people should give positive feelings less weight in their evaluations of the past.

Of course, nonprobative photos should sometimes encourage negative beliefs in the absence of these other factors. After all, the idea that photos bolster positive claims about the past by evoking positive feelings implies that photos can bolster negative claims as long as they evoke negative feelings. Suppose that the photos in our experiments had depicted animals that were creepy, deformed, or ugly. These "negative" photos would - like the more "neutral" photos - help people bring related thoughts and images to mind. But they would also activate relatively more negative associations, causing negative feelings that people would interpret as evidence for the negative claims (Bower, 1981; Lee \& Labroo, 2004). Such a possibility is worthy of investigation, particularly because the concern that people had developed negative false memories of abuse in therapy spurred much of the research on false autobiographical memories (Loftus, 1993).

This line of research is also important for understanding what kinds of images could increase innocent suspects' belief that they were involved in a crime, or jurors' belief that a defendant is guilty (Henkel, 2011; Henkel \& Carbuto, 2008; Newman \& Feigenson, 2013). An early study provided evidence that incidental cues present during retrieval can lead people to confess to doing things they did not do. People saw a list of words and were instructed to cross some of those words out. Afterward, people answered several unrelated questions about themselves, responding truthfully if they saw one colored light and lying if they saw a different colored light. Later, these "truth" and "lie" lights appeared as people confessed to crossing out words on the list, and the truth lights led people to report crossing out words when they really had not (Bem, 1966). Even though the lights were nonprobative with respect to what people really did, people used them as evidence about their pasts. The effects of photos demonstrated here are conceptually the same. The difference is that the 
lights worked through associations learned over the course of the experiment, whereas our photos worked through associations formed over a lifetime of experience that tells people that feeling good about the past means it probably was good.

One open question is whether nonprobative photos rapidly encouraged false memories, not just false beliefs. Put differently, to what extent did nonprobative photos cause the subjective experience of "remembering" experiences (recollecting details about events), as opposed to merely "knowing" those experiences occurred (feeling certain that the event happened, without recollecting details; Gardiner, 1988; Rajaram, 1993; Tulving, 1985)? Our findings do not answer this question, but some evidence suggests that photos would not have rapidly caused false memories. In one study, people decided whether they had seen target words (e.g., book) earlier in the experiment. When the target words appeared after related words (e.g., author), people more often thought they had seen them, as compared to when the target words appeared after unrelated words (e.g., tree). More to the point, related words increased people's reports of "knowing" they had seen words, but not of "remembering" (Rajaram \& Geraci, 2000; see also Rajaram, 1993; Wang \& Yonelinas, 2012). If photos operate like related words, by boosting access to related information, they should not produce the subjective experience of remembering - at least not immediately.

Nevertheless, "known" events can become "remembered" ones; when people spend time thinking about or imagining events they have claimed only to know happened, they subsequently rate those events as being more like ones they remember (Hyman, Gilstrap, Decker, \& Wilkinson, 1998; Paddock, Terranova, Kwok, \& Halpern, 2000). In fact, the mere conviction an event happened should encourage people to dwell on its details: If photos increase people's certainty that an event has happened, they should also increase people's confidence that they could retrieve details about that event (Mandler, 1980). Attempts at retrieving those details could turn what was once a feeling, a belief, into a detailed memory that people may ultimately mistake as evidence of genuine experience (Hyman \& Kleinknecht, 1999; Johnson et al., 1993; Lindsay, 2008, 2014; Lindsay et al., 2004). So, although nonprobative photos may not immediately create false memories, by making people more certain that events have happened, they should encourage the processes that do.

Another interesting question for future research is whether, when photos increase belief that the past was positive, they also would cause people to reconstruct past events as being more positive than they actually were. Research on choicesupportive memory biases suggests that photos would do just that. We know that people recall more positive than negative information about choices they believe they made, even if that belief is wrong - effects thought to arise because people assume that they typically make good choices, and that assumption biases them to recall positive aspects of the choice
(Benney \& Henkel, 2006; Henkel \& Mather, 2007). Similarly, when photos lead people to believe an experience was positive, they may bias people to recall more positive details about the experience. Through that route, photos could also increase nostalgia, decrease regret, and help to maintain people's overly positive impressions of the past (Walker, Skowronski, \& Thompson, 2003).

Author note E.J.N. is now located in the Dana and David Dornsife College of Letters, Arts, and Sciences of the University of Southern California. J.L.F. is now located in the Psychology Department of the University of Western Sydney. We are grateful for support from the New Zealand Government through the Marsden Fund, administered by the Royal Society of New Zealand on behalf of the Marsden Fund Council. We also thank Fran Gleisner, Matti Vuorre, and Adele Quigley-McBride for their help with data collection.

\section{References}

Alter, A. L., \& Oppenheimer, D. M. (2009). Uniting the tribes of fluency to form a metacognitive nation. Personality and Social Psychology Review, 13, 219-235. doi:10.1177/1088868309341564

Bem, D. J. (1966). Inducing belief in false confessions. Journal of Personality and Social Psychology, 3, 707-710. doi:10.1037/ h0023226

Benney, K. S., \& Henkel, L. A. (2006). The role of free choice in memory for past decisions. Memory, 14, 1001-1011. doi:10.1080/ 09658210601046163

Berinsky, A. J., Margolis, M. F., \& Sances, M. W. (2014). Separating the shirkers from the workers? Making sure respondents pay attention on self-administered surveys. American Journal of Political Science, 58, 739-753. doi:10.1111/ajps. 12081

Bernstein, D. M., Godfrey, R. D., \& Loftus, E. F. (2009). False memories: The role of plausibility and autobiographical belief. In K. D. Markman, W. M. Klein, \& J. A. Suhr (Eds.), Handbook of imagination and mental simulation (pp. 89-102). New York, NY: Psychology Press.

Bernstein, D. M., Whittlesea, B. W. A., \& Loftus, E. F. (2002). Increasing confidence in remote autobiographical memory and general knowledge: Extensions of the revelation effect. Memory \& Cognition, 30, 432-438. doi:10.3758/BF03194943

Blandon-Gitlin, I., \& Gerkens, D. (2010). The effects of photographs and event plausibility in creating false beliefs. Acta Psychologica, 135, 330-334. doi:10.1016/j.actpsy.2010.08.008

Bower, G. H. (1981). Mood and memory. American Psychologist, 36, 129-148. doi:10.1037/0003-066X.36.2.129

Brown, A. S., \& Marsh, E. J. (2008). Evoking false beliefs about autobiographical experience. Psychonomic Bulletin \& Review, 15, 186190. doi:10.3758/PBR.15.1.186

Cacioppo, J. T., Gardner, W. L., \& Berntson, G. G. (1999). The affect system has parallel and integrative processing components: Form follows function. Journal of Personality and Social Psychology, 76, 839-855. doi:10.1037/0022-3514.76.5.839

Chrobak, Q. M., \& Zaragoza, M. S. (2008). Inventing stories: Forcing witnesses to fabricate entire fictitious events leads to freely reported false memories. Psychonomic Bulletin \& Review, 15, 1190-1195. doi:10.3758/PBR.15.6.1190

Collins, A. M., \& Loftus, E. F. (1975). A spreading-activation theory of semantic processing. Psychological Review, 82, 407-428. doi:10. 1037/0033-295X.82.6.407 
Cumming, G. (2012). Understanding the new statistics: Effect sizes, confidence intervals, and meta-analysis. New York, NY: Routledge.

Devitt, A. L., Monk-Fromont, E., Schacter, D. L., \& Addis, D. R. (2015). Factors that influence the generation of autobiographical memory conjunction errors. Memory, 24, 204-222. doi:10.1080/09658211. 2014.998680

Downs, J. S., Holbrook, M. B., Sheng, S., \& Cranor, L. F. (2010). Are your participants gaming the system? Screening Mechanical Turk workers. In E. Mynatt, G. Fitzpatrick, S. Hudson, K. Edwards, \& T. Rodden (Eds.), Proceedings of the 28th International Conference on Human Factors in Computing Systems, CHI 2010 (pp. 2399-2402). New York, NY: ACM Press. doi:10.1145/1753326.1753688

Elliot, A. J. (2006). The hierarchical model of approach-avoidance motivation. Motivation and Emotion, 30, 111-116. doi:10.1007/s11031006-9028-7

Garcia-Marques, T., Mackie, D. M., Claypool, H. M., \& Garcia-Marques, L. (2013). Once more with feeling! Familiarity and positivity as integral consequences of previous experience. In C. Unkelbach \& R. Greifeneder (Eds.), The experience of thinking: How the fluency of mental processes influences cognition and behavior (pp. 50-69). New York, NY: Psychology Press.

Gardiner, J. M. (1988). Functional aspects of recollective experience. Memory \& Cognition, 16, 309-313. doi:10.3758/BF03197041

Gilbert, D. T. (1991). How mental systems believe. American Psychologist, 46, 107-119. doi:10.1037/0003-066X.46.2.107

Gill, M. J., Swann, W. B., \& Silvera, D. H. (1998). On the genesis of confidence. Journal of Personality and Social Psychology, 75, 1101-1114. doi:10.1037/0022-3514.75.5.1101

Goodman, J. K., Cryder, C. E., \& Cheema, A. (2013). Data collection in a flat world: The strengths and weaknesses of Mechanical Turk samples. Journal of Behavioral Decision Making, 26, 213-224. doi:10. 1002/bdm. 1753

Henkel, L. A. (2011). Photograph-induced memory errors: When photographs make people claim they have done things they have not. Applied Cognitive Psychology, 25, 78-86. doi:10.1002/acp.1644

Henkel, L. A., \& Carbuto, M. (2008). Remembering what we did: How source misattributions arise from verbalization, mental imagery, and pictures. In M. R. Kelley (Ed.), Applied memory (pp. 213-234). Hauppauge, NY: Nova Science.

Henkel, L. A., \& Mather, M. (2007). Memory attributions for choices: How beliefs shape our memories. Journal of Memory and Language, 57, 163-176. doi:10.1016/j.jml.2006.08.012

Higgins, E. T. (1998). The aboutness principle: A pervasive influence on human inference. Social Cognition, 16, 173-198. doi:10.1521/soco. 1998.16.1.173

Hyman, I. E., Jr., Gilstrap, L. L., Decker, K., \& Wilkinson, C. (1998). Manipulating remember and know judgments of autobiographical memories: An investigation of false memory creation. Applied Cognitive Psychology, 12, 371-386. doi:10.1002/(SICI)1099. 0720(199808)12:4

Hyman, I. E., Jr., \& Kleinknecht, E. E. (1999). False childhood memories: Research, theory, and applications. In L. M. Williams \& V. L. Banyard (Eds.), Trauma and memory (pp. 175-188). Thousand Oaks, CA: Sage.

Jacoby, L. L., \& Dallas, M. (1981). On the relationship between autobiographical memory and perceptual learning. Journal of Experimental Psychology: General, 110, 306-340. doi:10.1037/0096-3445.110.3. 306

Jacoby, L. L., Kelley, C. M., \& Dywan, J. (1989). Memory attributions. In H. L. Roediger III \& F. I. M. Craik (Eds.), Varieties of memory and consciousness: Essays in honor of Endel Tulving (pp. 391-422). Hillsdale, NJ: Erlbaum.

Johnson, M. K., Hashtroudi, S., \& Lindsay, D. S. (1993). Source monitoring. Psychological Bulletin, 114, 3-28. doi:10.1037/0033-2909. 114.1.3
Jones, T. C., \& Jacoby, L. L. (2001). Feature and conjunction errors in recognition memory: Evidence for dual-process theory. Journal of Memory and Language, 45, 82-102. doi:10.1006/jmla.2000.2761

Kapelner, A., \& Chandler, D. (2010, October). Preventing satisficing in online surveys: A "kapcha" to ensure higher quality data. Paper presented at CrowdConf, San Francisco, CA. Retrieved from www.crowdconf2010.com/images/finalpapers/kapelner.pdf

Lang, P. J., Bradley, M. M., \& Cuthbert, B. N. (1990). Emotion, attention, and the startle reflex. Psychological Review, 97, 377-395. doi:10. 1037/0033-295X.97.3.377

Lee, A. Y., \& Labroo, A. A. (2004). The effect of conceptual and perceptual fluency on brand evaluation. Journal of Marketing Research, 41, 151-165. doi:10.1509/jmkr.41.2.151.28665

Lindsay, D. S. (2008). Source monitoring. In H. L. Roediger III \& J. Byrne (Eds.), Learning and memory: A comprehensive reference: Vol. 2. Cognitive psychology of memory (pp. 325-348). Amsterdam, The Netherlands: Elsevier.

Lindsay, D. S. (2014). Memory source monitoring applied. In T. J. Perfect \& D. S. Lindsay (Eds.), The Sage handbook of applied memory (pp. 59-75). Los Angeles, CA: Sage.

Lindsay, D. S., Hagen, L., Read, J. D., Wade, K. A., \& Garry, M. (2004). True photographs and false memories. Psychological Science, 15, 149-154. doi:10.1111/j.0956-7976.2004.01503002.x

Loftus, E. F. (1993). The reality of repressed memories. American Psychologist, 48, 518-537. doi:10.1037/0003-066X.48.5.518

Loftus, E. F., Miller, D. G., \& Burns, H. J. (1978). Semantic integration of verbal information into visual memory. Journal of Experimental Psychology: Human Learning and Memory, 4, 19-31. doi:10. 1037/0278-7393.4.1.19

Mandler, G. (1980). Recognizing: The judgment of previous occurrence. Psychological Review, 37, 252-271. doi:10.1037/0033-295X.87.3. 252

Masson, M. E. J., \& Loftus, G. R. (2003). Using confidence intervals for graphically based data interpretation. Canadian Journal of Experimental Psychology, 57, 203-220. doi:10. $1037 / \mathrm{h} 0087426$

Monin, B. (2003). The warm glow heuristic: When liking leads to familiarity. Journal of Personality and Social Psychology, 85, 10351048. doi:10.1037/0022-3514.85.6.103

Newman, E. J., \& Feigenson, N. (2013). The truthiness of visual evidence. The Jury Expert: The Art and Science of Litigation Advocacy, 25, 1-6.

Newman, E. J., Garry, M., Bernstein, D. M., Kantner, J., \& Lindsay, D. S. (2012). Nonprobative photographs (or words) inflate truthiness. Psychonomic Bulletin \& Review, 19, 969-974. doi:10.3758/ s13423-012-0292-0

Newman, E. J., Garry, M., Unkelbach, C., Bernstein, D. M., Lindsay, D. S., \& Nash, R. A. (2015). Truthiness and falsiness of trivia claims depend on judgmental contexts. Journal of Experimental Psychology, 41, 1337-1348. doi:10.1037/xlm0000099

Nickerson, R. S. (1998). Confirmation bias: A ubiquitous phenomenon in many guises. Review of General Psychology, 2, 175-220. doi:10. 1037/1089-2680.2.2.175

Oppenheimer, D. M., Meyvis, T., \& Davidenko, N. (2009). Instructional manipulation checks: Detecting satisficing to increase statistical power. Journal of Experimental Social Psychology, 45, 867-872. doi:10.1016/j.jesp.2009.03.009

Paddock, J. R., Terranova, S., Kwok, R., \& Halpern, D. V. (2000). When knowing becomes remembering: Individual differences in susceptibility to suggestion. Journal of Genetic Psychology, 161, 453-468. doi:10.1080/00221320009596724

Price, T. F., Dieckman, L. W., \& Harmon-Jones, E. (2012). Embodying approach motivation: Body posture influences startle eyeblink and event-related potential responses to appetitive stimuli. Biological Psychology, 90, 211-217. doi:10.1016/j.biopsycho.2012.04.001 
Rajaram, S. (1993). Remembering and knowing: Two means of access to the personal past. Memory \& Cognition, 21, 89-102. doi:10.3758/ BF03211168

Rajaram, S., \& Geraci, L. (2000). Conceptual fluency selectively influences knowing. Journal of Experimental Psychology: Learning, Memory, and Cognition, 26, 1070-1074. doi:10.1037/0278-7393. 26.4.1070

Reber, R., Schwarz, N., \& Winkielman, P. (2004). Processing fluency and aesthetic pleasure: Is beauty in the perceiver's processing experience? Personality and Social Psychology Review, 8, 364-382. doi: 10.1207/s15327957pspr0804_3

Reber, R., Winkielman, P., \& Schwarz, N. (1998). Effects of perceptual fluency on affective judgments. Psychological Science, 9, 45-48. doi:10.1111/1467-9280.00008

Schwarz, N. (2004). Metacognitive experiences in consumer judgment and decision making. Journal of Consumer Psychology, 14, 332 348. doi:10.1207/s15327663jcp1404 2

Scoboria, A., Mazzoni, G., Kirsch, I., \& Relyea, M. (2004). Plausibility and belief in autobiographical memory. Applied Cognitive Psychology, 18, 791-807. doi:10.1002/acp.1062

Seamon, J. G., McKenna, P. A., \& Binder, N. (1998). The mere exposure effect is differentially sensitive to different judgment tasks. Consciousness and Cognition, 7, 85-102. doi:10.1006/ccog.1998. 0334

Song, H., \& Schwarz, N. (2008). Fluency and the detection of misleading questions: Low processing fluency attenuates the Moses illusion. Social Cognition, 26, 791-799. doi:10.1521/soco.2008.26.6.791

Stanislaw, H., \& Todorov, N. (1999). Calculation of signal detection theory measures. Behavior Research Methods, Instruments, \& Computers, 31, 137-149. doi:10.3758/BF03207704

Strange, D., Garry, M., Bernstein, D. M., \& Lindsay, D. S. (2011). Photographs cause false memories for the news. Acta Psychologica, 136, 90-94. doi:10.1016/j.actpsy.2010.10.006

Strange, D., Gerrie, M. P., \& Garry, M. (2005). A few seemingly harmless routes to a false memory. Cognitive Processing, 6, 237-242. doi:10. 1007/s10339-005-0009-7

Suengas, A. G., \& Johnson, M. K. (1988). Qualitative effects of rehearsal on memories for perceived and imagined complex events. Journal of Experimental Psychology: General, 117, 377-389. doi:10.1037/ 0096-3445.117.4.377

Thomas, A. K., Bulevich, J. B., \& Loftus, E. F. (2003). Exploring the role of repetition and sensory elaboration in the imagination inflation effect. Memory \& Cognition, 31, 630-640. doi:10.3758/ BF03196103

Thomas, A. K., \& Loftus, E. F. (2002). Creating bizarre false memories through imagination. Memory \& Cognition, 30, 423-431. doi:10. 3758/BF03194942

Topolinski, S., Likowski, T. U., Weyers, P., \& Strack, F. (2009). The face of fluency: Semantic coherence automatically elicits a specific pattern of facial muscle reactions. Cognition and Emotion, 23, 260-271. doi:10.1080/02699930801994112

Tulving, E. (1985). How many memory systems are there? American Psychologist, 40, 385-398. doi:10.1037/0003-066X.40.4.385

Unkelbach, C. (2007). Reversing the truth effect: Learning the interpretation of processing fluency in judgments of truth. Journal of Experimental Psychology: Learning, Memory, and Cognition, 33, 219-230. doi:10.1037/0278-7393.33.1.219

Wade, K. A., Garry, M., Read, J. D., \& Lindsay, D. S. (2002). A picture is worth a thousand lies: Using false photographs to create false childhood memories. Psychonomic Bulletin \& Review, 9, 597-603. doi: 10.3758/BF03196318

Walker, W. R., Skowronski, J. J., \& Thompson, C. P. (2003). Life is pleasant-And memory helps to keep it that way! Review of General Psychology, 7, 203-210. doi:10.1037/1089-2680.7.2.203

Wang, W., \& Yonelinas, A. P. (2012). Familiarity is related to conceptual implicit memory: An examination of individual differences. Psychonomic Bulletin \& Review, 19, 1154-1164. doi:10.3758/ s13423-012-0298-7

Westerman, D. L. (2008). Relative fluency and illusions of recognition memory. Psychonomic Bulletin \& Review, 15, 1196-1200. doi:10. 3758/PBR.15.6.1196

Whittlesea, B. W. A. (1993). Illusions of familiarity. Journal of Experimental Psychology: Learning, Memory, and Cognition, 19, 1235-1253. doi:10.1037/0278-7393.19.6.1235

Whittlesea, B. W. A., \& Williams, L. D. (2001a). The discrepancyattribution hypothesis: I. The heuristic basis of feelings of familiarity. Journal of Experimental Psychology: Learning, Memory, and Cognition, 27, 3-13. doi:10.1037/O278-7393.27.1.3

Whittlesea, B. W. A., \& Williams, L. D. (2001b). The discrepancyattribution hypothesis: II. Expectation, uncertainty, surprise, and feelings of familiarity. Journal of Experimental Psychology: Learning, Memory, and Cognition, 27, 14-33. doi:10.1037/02787393.27.1.14

Winkielman, P., \& Cacioppo, J. T. (2001). Mind at ease puts a smile on the face: Psychophysiological evidence that processing facilitation elicits positive affect. Journal of Personality and Social Psychology, 81, 989-1000. doi:10.1037/0022-3514.81.6.989

Winkielman, P., Halberstadt, J., Fazendeiro, T., \& Catty, S. (2006). Prototypes are attractive because they are easy on the mind. Psychological Science, 17, 799-806. doi:10.1111/j.1467-9280. 2006.01785.x

Winkielman, P., Schwarz, N., Fazendeiro, T., \& Reber, R. (2003). The hedonic marking of processing fluency: Implications for evaluative judgment. In J. Musch \& K. C. Klauer (Eds.), The psychology of evaluation: Affective processes in cognition and emotion (pp. 189217). Mahwah, NJ: Erlbaum.

Zaragoza, M. S., \& Lane, S. M. (1998). Processing resources and eyewitness suggestibility. Legal and Criminological Psychology, 3, 305320. doi:10.1111/j.2044-8333.1998.tb00368.x 